\title{
CARACTERIZAÇÃO ERITROCITOMÉTRICA DIFERENCIAL ENTRE PORTADORES DE ANEMIA POR DEFICIÊNCIA DE FERRO, TRAÇO FALCIFORME E BETA TALASSEMIA MENOR
}

\section{CHARACTERIZATION ERYTHROCYTARY DIFFERENTION AMONG IRON DEFICIENCY, HETEROZYGOUS SICKLE DISEASE AND BETA THALASSEMIA MINOR}

\author{
${ }^{*}$ Railson Henneberg \\ *Professor Assistente - Universidade Federal do Paraná - UFPR - Departamento de \\ Patologia Médica - Campus Botânico - Curitiba - Paraná. \\ ${ }^{* *}$ Amauri Antiquera Leite \\ **Professor Doutor - Faculdade de Ciências Farmacêuticas - Departamento de Análises \\ Clínicas - UNESP - Campus Araraquara - São Paulo. \\ *** Aguinaldo José do Nascimento \\ ***Professor Sênior - Programa de Pós-Graduação em Ciências Farmacêuticas - UFPR - \\ Curitiba - Paraná \\ e-mail para contato: railson@ufpr.br \\ RECEBIDO: 11/06/08 ACEITO: 05/07/08
}

\begin{abstract}
RESUMO:
O número de funções discriminantes baseadas na automação, incorporou vários parâmetros relacionados ás células eritrocitárias, que foram desenvolvidas para diferenciar as várias formas de anemia. $O$ objetivo deste trabalho, foi estabelecer padrões de diferenciação através dos índices eritrocitométricos em três estados patológicos do metabolismo da hemoglobina: a deficiência de ferro, o traço falciforme e a beta talassemia menor. A deficiência de ferro foi caracterizada em pacientes com níveis de ferritina abaixo de $10 \mathrm{ng} / \mathrm{dL}$, enquanto que a beta talassemia menor e o traço falciforme foram definidas pela resistência osmótica alterada, teste de solubilidade para a hemoglobina $S$ e eletroforese de hemoglobina. O grupo de talassêmicos revelou característica marcante em relação à elevada contagem de eritrócitos (acima de 5 milhões $/ \mathrm{mm}^{3}$ ), diminuição do VCM e HCM (respectivamente abaixo de $71 \mathrm{fL}$ e $24 \mathrm{pg}$ ) e presença de ponteado basófilo em todas as extensões sangüíneas analisadas, já no grupo deficiente de ferro houve grande variação quanto ao grau de microcitose e hipocrômia, podendo apresentar parâmetros semelhantes aos encontrados na beta talassemia menor. Por outro lado, o grupo de portadores do traço falciforme, apresentaram normocitose e normocromia . A elevação do RDW acima de $20 \%$ foi encontrada apenas no grupo deficiente de ferro, porém valores acima do normal $(14,5 \%)$ foram encontrados nas três patologias, dificultando uma diferenciação por este parâmetro. Nosso estudo permite concluir que é possível presumir os portadores de beta talassemia menor, diferenciando-os daqueles portadores de anemia por deficiência de ferro e solicitar eletroforese de hemoglobina quantitativa, mas não é possível suspeitar dos que seriam portadores do traço falciforme, apenas pelos dados do eritrograma.
\end{abstract}

Palavras-Chave: eritrograma, traço falciforme, beta talassemia, deficiência de ferro.

\section{ABSTRACT:}

The number of discriminating functions based on automations have incorporated some parameters related to erythrocyte that had been developed to differentiate several forms of anemias. The aim of this work was to establish standards of differentiation through erythrocytometric indices in three pathological states of the hemoglobin metabolism: the iron deficiency, the sickle cell anemia and the B-thalassemia minor. The iron deficiency was characterized in patients with ferritin levels below of $10 \mathrm{ng} / \mathrm{dL}$, whereas B-thalassemia minor and the the sickle cell anemia had been defined by the modified osmotic resistance, hemoglobin 
$S$ solubility test for the hemoglobin electrophoresis. The thalassemic group disclosed an outstanding characteristic related to the higher erythrocyte counting (above of 5 milhões $/ \mathrm{mm}^{3}$ ), reduced MCV and $\mathrm{MCH}$ (below $71 \mathrm{fL}$ and $24 \mathrm{pg}$, respectively) and presence of point of basophilic stippling in all the May-Grünwald-Giemsa stained smear. In the iron deficient group it was observed great variation on the microcytosis and hypocromia degree, and similar parameters as the ß-thalassemia minor. On the other hand, the sickle cell group presented normocytosis and normocromia. RDW values above $20 \%$ was found only in the iron deficient group, although values above-normal (14.5\%) had been found in the three pathologies studied, making it difficult a differentiation using this parameter. Our results suggest that it is possible to suspect of $B$ thalassemia minor carriers, differentiating them of those carriers of anemia for iron deficiency prior to the request for quatitative hemoglobin electroforesis. From the erythrogram data alone it is not possible to identify the ones carriers of sickle cell anemia.

Key-words: erythrogram, heterozygous sickle cell disease, beta-thalassemia minor, iron deficiency

\section{INTRODUÇÃO}

A utilização de autoanalisadores na hematologia melhorou o diagnóstico das diferentes anemias, proporcionando resultados seguros e novos parâmetros hematológicos. O objetivo primário destes parâmetros é providenciar, de maneira simples, a diferenciação das causas mais comuns de anemia, que apresentam aspectos morfológicos semelhantes (GREEN e KING, 1989). Com o avanço da tecnologia utilizada nos contadores hematológicos eletrônicos, foram introduzidos novos índices hematimétricos, dentre eles o RDW (Red Cell Distribution Width), índice de dispersão da anisocitose, que tem sido apontado por vários autores como de grande utilidade no diagnóstico diferencial de algumas anemias (SILVA et al, 1997).

Vários estudos têm demonstrado que as anemias podem ser classificadas de acordo com o VCM, o RDW e os histogramas de distribuição de tamanhos obtidos pelos autoanalisadores (ARTAZA et al, 1999), onde relata-se, a maior utilidade do RDW, como indicador mais sensível que o VCM para estabelecer a possível etiologia de anemias microcíticas (GUERRA - SHINOHARA et al,1999).

O traço falciforme é caracterizado pela heterozigose para a presença de globina $b^{\text {s, }}$, de modo que estão presentes hemoglobina $S$ e hemoglobina $A$, apresentando o genótipo $b / b^{s}$. Pacientes portadores do traço falciforme são geralmente assintomáticos, não havendo manifestações clínicas e hematológicas importantes (RODAK, 1995). Vários autores relatam que tanto a morfologia eritrocitária quanto os índices eritrocitários são normais (CORRONS, 1994; MCKENZIE, 1996; RODAK, 1995), porém, outros ressaltam que pode haver, em alguns casos, a redução do VCM e da HCM, por este motivo, o diagnóstico diferencial do traço falciforme deve ser feito em relação a outras causas de microcitose (BAIN , 1997).

O estado heterozigótico da beta talassemia menor é caracterizado geneticamente pela herança de um único componente alterado. Nas formas bo e $b^{+}$heterozigóticas, a redução da taxa de síntese da globina beta é menor, mas o suficiente para causar discreto grau de anemia microcítica e hipocrômica com aumento da resistência osmótica dos eritrócitos (NAOUM, 2001). Os portadores heterozigotos de b-talassemia apresentam uma discreta anemia microcítica e hipocrômica, evidenciada por um VCM e HCM inferiores aos valores normais, associados à concentração aumentada de hemoglobina $A_{2}$ (4 a 8\%) (RUND,1992; WEATHERALL, 1997).

Por ser uma anemia microcítica moderada, a beta talassemia pode ser diagnosticada como anemia por deficiência de ferro, quando o diagnóstico se baseia apenas em dados eritrocitométricos e aspectos morfológicos, com a possibilidade de um tratamento desnecessário

Visão Acadêmica, Curitiba, v.9, n.2, Jul. - Dez./2008 - ISSN 1518-5192 
com ferro. A diferenciação das anemias microcíticas é de grande importância clínica, particularmente em populações que possuem várias etnias por apresentarem diferentes causas, patogênese, prognóstico e tratamentos (ELDIBANY, 1999).

A deficiência de ferro é conhecida como a carência nutricional mais comum do mundo. Em países em desenvolvimento, a prevalência da anemia por deficiência de ferro tem diminuído rapidamente nas últimas décadas, enquanto que o número de casos do estado subclínico da deficiência permanece significante. Os testes convencionais utilizados para a avaliação do metabolismo do ferro, como ferro sérico, capacidade total de ligação do ferro (CTLF), índice de saturação (IST\%), e a ferritina sérica são utilizados com freqüência na prática clínica, embora deva-se considerar as influências que estas análises possuem (PUNNONEN, 1997).

A anemia por deficiência de ferro é definida, pela Organização Mundial de Saúde (SILVA et al, 1997), como um estado patológico em que níveis sangüíneos de hemoglobina estão menores que $13 \mathrm{~g} / \mathrm{dL}$ para homens, $12 \mathrm{~g} / \mathrm{dL}$ para mulheres e menores que $11 \mathrm{~g} / \mathrm{dL}$ para crianças e gestantes. Nestas condições pode haver diminuição do hematócrito, de hemoglobina corpuscular média (HCM) e do volume corpuscular médio (VCM). O ferro sérico apresenta-se diminuído, a porcentagem de saturação da transferrina (IST\%) está menor que $16 \%$, a ferritina sérica inferior a $12 \mathrm{ng} / \mathrm{dL}$, ocorrendo aumento na capacidade total de ligação de ferro e dos receptores de transferrina (LERNER, 1994).

Todos os componentes dependentes de ferro, ou que estão envolvidos em seu metabolismo, devem ser analisados para identificar além da anemia propriamente dita, também os estágios anteriores ao seu desenvolvimento. Para isto, parâmetros tanto hematológicos quanto bioquímicos necessitam ser avaliados em conjunto possibilitando a distinção das etapas progressivas do desenvolvimento da deficiência de ferro. Beutler e Fairbanks (2001) utilizaram a concentração de ferritina abaixo de $10 \mathrm{ng} / \mathrm{dL}$ como característica de anemia por deficiência de ferro, valores entre 10 a $20 \mathrm{ng} / \mathrm{dL}$, como indicativo de deficiência de ferro sem anemia e ferritina abaixo de $50 \mathrm{ng} / \mathrm{dL}$, porém acima de $20 \mathrm{ng} / \mathrm{dL}$, um estágio onde começa a depleção dos estoques de ferro, o que poderia refletir os estágios da deficiência de ferro.

O objetivo do trabalho foi procurar estabelecer padrões eritrocitários de caracterização e diferenciação, através de comparação de valores eritrocitométricos, em três etiologias relacionadas à alteração do metabolismo eritrocitário.

\section{MATERIAL E MÉTODOS}

Foram realizados 637 eritrogramas em diferentes grupos de estudo. Como o trabalho propôs comparar valores eritrocitométricos, foi necessária a composição de um grupo controle. Para isto foram estudados doadores de sangue, adultos, que compareceram ao Núcleo de Hematologia e Hemoterapia da Regional de Araraquara Professora Clara Pechmann Mendonça - Hemonúcleo de Araraquara, da Faculdade de Ciências Farmacêuticas da UNESP.

As amostras sanguíneas, coletadas em tubos a vácuo com EDTA-K3 (Vacutainer, Becton-Dickinson), de todos os participantes dos quatro grupos de estudo (controle, talassêmicos, traço falciforme e deficientes de ferro) foram analisadas em contador eletrônico de células sanguíneas de 22 parâmetros da marca Coulter, modelo STKS. Através destes eritrogramas foi possível obter os valores eritrocitométricos de contagem de glóbulos vermelhos, hemoglobina, hematócrito, volume corpuscular médio (VCM), hemoglobina corpuscular média (HCM), concentração de hemoglobina corpuscular média ( $\mathrm{CHCM}$ ) e amplitude de distribuição eritrocitária (ADE ou RDW).

O grupo controle foi constituído de 416 doadores de sangue, sendo 68 mulheres e 348 homens, que compareceram ao serviço de Hemoterapia de Araraquara. Os valores encontrados para o grupo controle estão próximos àqueles valores de referência propostos 
pela literatura (MCKENZIE, 1996; RODAK, 1995), mostrando ser pertinente o uso destes valores para comparação com os encontrados nos grupos estudados.

A amostragem para a composição do grupo de deficientes de ferro foi obtida no Laboratório de Análises Clínicas, que presta serviço ao Hospital Beneficiência Portuguesa de Araraquara, São Paulo. Amostras que apresentaram dosagem de ferro sérico abaixo de 50 $\mathrm{mg} / \mathrm{dL}$ (International Committe for standardization in Haematology, 1978) e dosagem de ferritina abaixo de $10 \mathrm{ng} / \mathrm{dL}$ (MILES,1974), foram encaminhadas para a realização de eritrograma. $O$ grupo de deficientes de ferro, ficou constituído por 40 pacientes.

A seleção dos portadores do traço falciforme, baseou-se na resistência osmótica alterada, positividade das amostras ao teste de solubilidade para a hemoglobina S adaptado para microplaca (PENTEADO, 2001) e confirmação destes achados, por eletroforese em meio alcalino, para a verificação da característica corrida eletroforética para hemoglobina AS. Foram realizados 106 eritrogramas de portadores AS, sendo 56 pacientes do sexo feminino e 50 do sexo masculino.

Foram avaliados 44 portadoras e 31 portadores de beta talassemia menor, que tiveram teste de resistência osmótica à $0,36 \%$ alterada, seguida de teste de solubilidade para a hemoglobina $\mathrm{S}$ negativo. Eletroforese em $\mathrm{pH}$ alcalino foi realizada para a confirmação da fração $A_{2}$ aumentada (acima de $3,7 \%$ ). Após estes procedimentos, os eritrogramas foram realizados.

As distensões sangüíneas de todas as amostras foram analisadas para a observação de alterações morfológicas da população eritrocitária, bem como a presença ou não de inclusões citoplasmáticas. Os dados foram avaliados com o uso de análise de variância, modelo inteiramente casualizado, seguido do Teste de Tukey para classificação das médias. A significância estatística foi considerada para $p<0,05$.

\section{RESULTADOS}

Os grupos estudados foram divididos em: grupo controle $(n=416)$; beta talassêmicos $(n=75)$; deficientes de ferro $(n=40)$ e o grupo de portadores do traço falciforme $(n=106)$. A tabela 1 ilustra as médias e desvio padrão dos índices eritrocitométricos estudados. Os resultados obtidos indicam que as médias dos índices eritrocitários dos indivíduos portadores de traço falciforme, beta talassêmicos e os ferropênicos foram todos estatisticamente diferentes (ANOVA $p<0,05)$ das médias do grupo controle.

No que diz respeito aos beta talassêmicos, na contagem de eritrócitos observa-se valores mais elevados em relação aos grupos controle, deficientes de ferro e os portadores AS, o que confirma relatos da literatura $(M E L O, 2002)$ a respeito da elevada hematimetria nestes pacientes.

As três patologias estudadas apresentaram concentração de hemoglobina inferior ao grupo controle. Comparando os talassêmicos e os portadores da deficiência de ferro não houve diferença estatisticamente significativa (média 11g/L). Em relação ao hematócrito o perfil é parecido com a da hemoglobina, onde todos os grupos apresentam valores inferiores ao grupo controle, e que não há diferença entre os valores médios dos talassêmicos e ferropênicos.

O parâmetro que apresentou maior discrepância entre os talassêmicos e os outros grupos foi o VCM, com valor médio de $64 \mathrm{fL}$ para os talassêmicos, $89 \mathrm{fL}$ para o grupo controle, $77 \mathrm{fL}$ para os ferropênicos e $87 \mathrm{fL}$ para os portadores AS. Em 93\% dos talassêmicos foi encontrado valores de VCM abaixo de $70 \mathrm{fL}$ e quando aplicado valor de corte de $71 \mathrm{fL}$, todos os pacientes apresentaram este perfil. Em relação aos ferropênicos somente $25 \%$ dos pacientes apresentaram valores de VCM inferiores a $70 \mathrm{fL}$. 
Igualmente ao VCM, a média do HCM dos talassêmicos (20pg) é bem abaixo do encontrado no grupo controle (30pg). Os ferropênicos e os portadores AS também apresentam HCM médios inferiores (24pg e 28pg, respectivamente) ao controle. Nenhum paciente beta talassêmico apresentou valores de HCM acima de 27pg.

Com relação ao CHCM todos os valores médios dos grupos patológicos foram inferiores ao grupo controle. Não há diferença estatística entre os beta talassêmicos $(31,9 \mathrm{~g} /$ $\mathrm{dL}$ ) e os ferropênicos $(31,9 \mathrm{~g} / \mathrm{dL})$. O CHCM demonstra-se não ser um parâmetro confiável para o diagnóstico diferencial, pois as diferenças encontradas entre os grupos é muito pequena.

Os valores médios de RDW são muito maiores nos grupos beta talassêmicos e ferropênicos quando comparados com o grupo controle e portador AS $(p<0,05)$. Analisando somente os grupos beta talassemia e deficientes de ferro há diferenças significantes $(p<0,05)$, com valores mais elevados nos ferropênicos em relação ao grupo de talassêmicos. Em $68,5 \%$ dos ferropênicos, o RDW apresentou-se acima dos valores de normalidade (14,5\%) com grandes variações de valores e possibilidade de índices extremos (até $25,8 \%$ ). Comparando as três patologias estudadas, as médias dos valores de RDW foram normais nos portadores do traço falciforme $(13,5 \%)$ e próximas na beta talassemia $(15,62 \%)$ e nos deficientes de ferro $(16,56 \%)$.

Outro achado importante encontrado neste estudo, foi a absoluta correlação entre a beta talassemia e a presença de ponteado basófilo nas extensões sanguíneas, o que não foi encontrada nas outras duas patologias estudadas.

TABELA 1 - Valores eritrocitométricos médios para os grupos controle e grupos patológicos.

\begin{tabular}{|c|c|c|c|c|}
\hline Parâmetros & $\begin{array}{l}\text { Controle } \\
(N=416)\end{array}$ & $\begin{array}{c}\beta \text {-talassemia } \\
(\mathrm{N}=75)\end{array}$ & $\begin{array}{l}\text { Ferropênicos } \\
(\mathrm{N}=40)\end{array}$ & $\begin{array}{c}\text { Grupo AS } \\
(\mathrm{N}=106)\end{array}$ \\
\hline$\overline{\mathrm{GV}}\left(10^{6} / \mathrm{mm}^{3}\right)$ & $4,72 \pm 0,42$ & $5,68 \pm 0,65$ & $4,54 \pm 0,53$ & $4,54 \pm 0,54$ \\
\hline $\mathrm{Hb}(\mathrm{g} / \mathrm{dL})$ & $14,10 \pm 1,11$ & $11,66 \pm 1,32$ & $11,13 \pm 1,60$ & $13,06 \pm 1,42$ \\
\hline $\mathrm{Ht}(\%)$ & $41,98 \pm 3,69$ & $36,51 \pm 4,10$ & $34,80 \pm 4,29$ & $39,42 \pm 4,18$ \\
\hline VCM(fL) & $89,40 \pm 5,47$ & $64,32 \pm 3,16$ & $77,40 \pm 11,31$ & $87,28 \pm 6,19$ \\
\hline $\mathrm{HCM}(\mathrm{pg})$ & $29,96 \pm 1,95$ & $20,55 \pm 1,07$ & $24,76 \pm 4,18$ & $28,91 \pm 2,27$ \\
\hline CHCM(g/dL) & $33,48 \pm 0,73$ & $31,94 \pm 0,56$ & $31,89 \pm 1,10$ & $33,08 \pm 0,77$ \\
\hline RDW(\%) & $12,88 \pm 0,88$ & $15,62 \pm 1,13$ & $16,56 \pm 3,36$ & $13,48 \pm 1,69$ \\
\hline
\end{tabular}

\section{DISCUSSÃO}

A apreciação do tamanho e conteúdo hemoglobínico dos eritrócitos a partir da extensão sangüínea tem sido, durante anos, uma das maneiras de estudar as anemias em laboratório. A fim de melhorar o caráter subjetivo inerente ao exame morfológico, Wintrobe propôs os chamados índices eritrocitários, obtidos por cálculo matemático a partir da contagem eritrocitária, do hematócrito e da concentração de hemoglobina (CORRONS, 1994). A utilização d automação na hematologia proporcionou resultados mais seguros e novos parâmetros hematológicos.

Atualmente as anemias podem ser classificadas de acordo com o VCM, o RDW e os histogramas de distribuição de tamanhos obtidos pelos autoanalisadores (ARTAZA, et al, 1999), onde relata-se, a maior utilidade do RDW, como indicador mais sensível que o VCM para estabelecer a possível etiologia de anemias microcíticas (GUERRA-SHINOHARA et al, 1999). 
Dentre as duas mais freqüentes causas congênitas ou adquiridas de anemias microcíticas, estão a beta talassemia menor e a anemia por deficiência de ferro (GREEN \& KING, 1989).

Esta pesquisa procurou estabelecer parâmetros de diferenciação entre três patologias relacionadas com alteração, seja ela, congênita ou adquirida, do metabolismo eritrocitário; o traço falciforme, a beta talassemia e a deficiência de ferro. Assim foram formados grupos de portadores das três patologias e um grupo controle, formado por doadores de sangue sadios de ambos os sexos.

Após a obtenção dos índices eritrocitométricos dos grupos estudados, determinamos as médias destes índices, e os desvios padrão, demonstrando que todos os grupos patológicos apresentaram diferenças estatísticas significantes dos índices eritrocitométricos em relação ao grupo controle $(p<0,05)$. Em resumo, encontramos um perfil característico na beta talassemia menor, uma grande variação de alguns índices eritrocitários para a deficiência de ferro, o que demonstra ser uma patologia de difícil caracterização e um quadro de normocitose e normocromia na maioria dos portadores do traço falciforme.

Nos últimos anos, a busca por parâmetros de diferenciação entre as anemias tem se intensificado. Green e King (1989), relatam várias diferenças que existem nos índices hematimétricos quando se compara a beta talassemia menor e a anemia por deficiência de ferro. Na patologia congênita, o grau de microcitose é maior que na deficiência de ferro, conseqüentemente o VCM tende a ser menor e a contagem de eritrócitos maior do que na doença adquirida. Porém, Artaza e colaboradores (1999), quando compararam, valores de VCM nas mesmas patologias, não encontraram diferenças significativas.

Resultados parecidos com os encontrados por Green e King (1989), também são relatados por England e Frase (1973) e Eldibany e colaboradores (1999), os quais observaram que para um mesmo grau de anemia, os eritrócitos na beta talassemia são mais microcíticos do que na anemia por deficiência de ferro.

O RDW é um parâmetro que pode avaliar populações eritrocitárias heterogêneas, sendo muito útil na confirmação do grau de anisocitose e diferenciar tipos de anemias. GuerraShinohara e colaboradores (1999), relatam que o RDW está aumentado na deficiência de ferro e normal ou levemente aumentado na beta talassemia menor. Em nosso estudo 81,8\% das mulheres e 90,3\% dos homens beta talassêmicos menores apresentaram índices de RDW acima de 14,5\%, usado como valor de normalidade. Artaza e colaboradores (1999) relatam o RDW como critério discriminante útil em diagnóstico diferencial nas anemias microcíticas, porém, outros estudos (BAIN, 1997), descrevem o RDW como sendo menos útil quando mais se precisa dele, porque o RDW também eleva-se naqueles pacientes beta talassêmicos que tornaram-se anêmicos. Alguns observadores ainda descrevem aumento do RDW em beta talassêmicos mesmo sem anemia (MARSH, 1987).

Os resultados encontrados em nosso trabalho a respeito do comportamento do RDW na beta talassemia e a anemia por deficiência de ferro, coincidem com o trabalho de Melo e colaboradores (2002), que consideraram a sensibilidade encontrada para este índice insuficiente para a utilização isolada deste parâmetro como teste de diferenciação entre a deficiência de ferro e a beta talassemia. Comparando as três patologias estudadas, as médias de valores de RDW foram normais nos portadores do traço falciforme (13,45\%) e parecidos na beta talassemia $(15,62 \%)$ e na deficiência de ferro(16,56). Em relação a beta talassemia e a deficiência de ferro houve diferença estatisticamente significante entre as duas patologias $(p<0,05)$, com grande variação de valores na deficiência de ferro, com possibilidades de índices extremos (até $25,8 \%$ ), enquanto que nos talassêmicos, apesar de valores acima do normal (14,5\%), o desvio padrão foi menor. Em nosso estudo houve correlação de valores de RDW entre as duas patologias, portanto, valores ligeiramente aumentados de RDW não puderam ser utilizados como diferenciação, necessitando da associação de outros parâmetros. 
Valores de RDW acima de $20 \%$ foram encontrados apenas nos indivíduos deficientes de ferro, enquanto que valores abaixo deste nível, foram vistos tanto na beta talassemia menor quanto na anemia por deficiência de ferro, o que pode ser usado para diferenciar somente nestas condições (RDW acima de $20 \%$ ) as duas patologias.

O grupo de beta talassêmicos apresentou uniformidade nos dados do eritrograma, com destaque para a elevada hematimetria (eritrócitos acima de 5 milhões $/ \mathrm{mm}^{3}$ ), VCM e HCM baixos ( abaixo de $70 \mathrm{fL}$ e $24 \mathrm{pg}$ ), além da presença de ponteado basófilo em todas as extensões analisadas no grupo. Estudo feito anteriormente (MELO, 2002) cita o valor de 5 milhões $/ \mathrm{mm}^{3}$ de glóbulos vermelhos, como índice discriminante na triagem de beta talassêmicos, quando 0 clínico depara-se com microcitose e níveis discretos de anemia. Em nosso estudo este dado é confirmado, pois tanto homens e mulheres estudadas, apresentaram hematimetria elevada em comparação aos outros grupos estudados.

Os achados encontrados nas contagens de eritrócitos confirmam relatos da literatura, onde o diagnóstico presuntivo é mais fácil de ser feito a partir desta contagem do que pela morfologia das extensões sangüíneas (BAIN, 1997). Nos beta talassêmicos do sexo masculino $(\mathrm{N}=31), 93 \%$ dos pacientes apresentaram contagens de eritrócitos acima de 2 desvio padrão do valor médio encontrado para o grupo controle $\left(5,55.10^{6} / \mathrm{mm}^{3}\right)$, enquanto que $81,8 \%$ das mulheres apresentaram contagens acima de 4,95.106/ $\mathrm{mm}^{3}$.

O eritrograma dos deficientes de ferro apresentou grande variabilidade de resultados, o que dificultou a caracterização hematológica deste grupo em relação ao eritrograma. A deficiência de ferro geralmente ocorre de forma gradual e progressiva, sendo o resultado final de um longo período de balanço negativo do ferro.(LEE, 1998). A principal conseqüência é a anemia, mas antes que esta se manifeste, três estágios são identificados, sendo muito difícil a caracterização destas etapas através dos exames bioquímicos tradicionais e do eritrograma (PAIVA, 2000).

No grupo de deficientes de ferro, a maioria dos pacientes apresentou contagem de eritrócitos abaixo de 4,95 milhões $/ \mathrm{mm}^{3}$, valor que comparado com o perfil dos talassêmicos torna-se um parâmetro de diferenciação entre as duas patologias. Com relação ao VCM, somente $25 \%$ dos ferropênicos apresentaram valores abaixo de $70 \mathrm{fL}$, faixa predominante nos beta talassêmicos. O grupo deficiente de ferro apresentou média de valores de VCM igual a $77,40 \mathrm{fL}$, com variações entre $58,5 \mathrm{fL}$ até $98,2 \mathrm{fL}$, o que demonstra a significativa variação de valores para este parâmetro, contrastando com os $64,1 \mathrm{fL}$ de média encontrados nos talassêmicos. Em relação ao HCM, $71,4 \%$ dos ferropênicos apresentaram valores abaixo de $27 \mathrm{pg}$, o que demonstra que a maioria dos pacientes deficientes de ferro apresentaram diminuição de peso de hemoglobina, que está relacionado com o estágio da deficiência de ferro.

A microcitose e a hipocromia são parâmetros básicos utilizados para o diagnóstico de anemia por deficiência de ferro e beta talassemia menor. Pudemos verificar uma marcante diminuição destes índices em 100\% $(p<0,05)$ dos portadores talassêmicos, com VCM abaixo de $71 \mathrm{fL}$ e HCM abaixo de $24 \mathrm{pg}$. Para os ferropênicos, também foi verificado predominância de microcitose e hipocromia, mas apenas $28,3 \%$ delas apresentaram valores dos índices semelhantes aos encontrados na beta talassemia menor. A variação destes valores demonstrou que pode haver uma diminuição parecida nestes dois índices eritrocitométricos (VCM e HCM), com sobreposição de valores em alguns casos de deficiência de ferro e beta talassemia menor, o que dificultaria a distinção entre estas patologias nesta parcela de indivíduos. Em nosso estudo pudemos comprovar que a grande maioria dos portadores do traço falciforme, apresenta população eritrocitária normocítica ( $90 \%$ dos homens e $75 \%$ das mulheres) com VCM acima de $82 \mathrm{fL}$, sem presença de anisocitose ( $90 \%$ dos homens e $82,2 \%$ das mulheres), com valores de RDW inferiores a $14,5 \%$. 
Quando da observação das distensões sangüíneas, houve absoluta correlação entre beta talassemia menor e a presença de ponteado basófilo, fato não observado para o traço falciforme e deficientes de ferro. Todos os beta talassêmicos apresentaram presença de graus variados de ponteado basófilo, o que associado a elevada contagem de glóbulos vermelhos e valores de VCM próximos ou menores de 70 fL, constituem quadro marcante na investigação laboratorial da beta talassemia menor.

\section{CONCLUSÃO}

Através da comparação entre o grupo controle estudado e os portadores do traço falciforme, houve diferenças estatísticas significantes nos dados do eritrograma $(p<0,05)$, porém este grupo patológico apresenta população eritrocitária predominatemente normocítica e sem presença de anisocitose. Portanto seu reconhecimento não é possível sem o uso de metodologia específica.

Os beta talassêmicos apresentaram marcante microcitose (VCM abaixo de $71 \mathrm{fL}$ ) e hipocromia (HCM abaixo de 24pg), com presença de ponteado basófilo em todas as extensões sangüíneas estudadas. Estes dados aliado a contagem de glóbulos vermelhos acima de 5 milhões $/ \mathrm{mm}^{3}$, constitui quadro marcante para o diagnóstico de beta talassemia menor.

Os dados obtidos para o grupo portador de deficiência de ferro são bastante heterogêneos, não sendo possível obter um padrão eritrocitométrico característico para esta patologia. Apenas naqueles indivíduos onde existe a presença de microcitose variável, hipocromia e anisocitose com o RDW superior a $21 \%$, pode ser indicativo de anemia por deficiência de ferro.

Quando da comparação entre a beta talassemia menor e a deficiência de ferro, a diferenciação é mais complicada. Quando encontra-se valores de VCM e HCM extremamente baixos, valores de RDW acima de $21 \%$, este perfil é indicativo de anemia por deficiência de ferro, porém, valores abaixo deste limite podem ser encontrados igualmente nestas duas alterações eritrocitárias, o que limita a utilização deste parâmetro, como fator de diferenciação. Nestes casos, a presença de ponteado basófilo pode ser um achado discriminante entre a deficiência de ferro e a beta talassemia menor.

A complexidade do estudo destas patologias, principalmente o diagnóstico correto da anemia por deficiência de ferro, demonstra que a maioria dos pedidos médicos não são suficientes para uma correta investigação de anemias, pois na maioria das vezes se resumem ao pedido do ferro sérico e do eritrograma. Nosso estudo demonstra claramente que apenas estes exames não são metodologias inteiramente confiáveis na diferenciação entre as três patologias estudadas em adultos, devendo-se haver investigação mais específica. Porém, a utilização de parâmetros eritrocitométricos, obtidos em contadores eletrônicos, podem em algumas condições caracteizar certos tipos de anemias microcíticas e hipocrômicas, como a beta talassemia menor.

\section{REFERÊNCIAS}

ARTAZA, J.R.; CARBIA, C.D.; CEBALLO, M.F.; DIAZ, N.B. Índice de distribucion de glóbulos rojos (RDW): Su aplicacion em la caracterizacion de anemias microcíticas e hipocromicas. Medicina, Buenos Aires, 1999, v. 59, p.17-22.

BAIN, B.J. Células sangüíneas: Um guia prático. 2ํed. Porto Alegre, Artes Médicas. 1997, $334 \mathrm{p}$. 
BESSMAN, D.; FEINSTEIN, D.I. Quantitative anisocytosis as discriminant between iron deficiency and thalassemia minor. Blood, Washington, 1979, v.53, p.288-293.

BEUTLER,E.; FAIRBANKS,V.F. Iron deficiency. In: Williams-Hematology, $6^{\text {th }}$. New York, McGraw-Hill, 2001, p.447-470.

CORRONS, J.L.V. Introdución al studio de la patologia retroatario. Bases bioquímicas y fisiológicas. In: J. Sans - Sabrafen/Hematologia Clinica, 3o ed., Madrid, España: Mosby Doyma S.A. ; 1994. p.119.

ELDIBANY, M.M.; TOTONCHI, K.F.; JOSEPH, N.J.; RHONE, D. Usefulness of certain red blood cell indices in diagnosing and differentiating thalassemia trait from iron - deficiency anemia. American Journal of Clinical Phatology, Chicago, 1999, v.111, p. $676-682$.

ENGLAND,J.M.; FRASE,P.M. Differentiation of iron deficiency form thalassaemia trait by routine blood-count. Lancet, Oxford, 1973, v.1, p.449-452.

FAILACE, R.; ANTUNES, C.M. O hemograma no Cell-Dyn 4000 no diagnóstico diferencial entre beta talassemia minor e anemia ferropênica. Laes\&Haes, São Paulo, 2003, ed. 142 Abril-Maio.

GREEN, R.; KING, R. A new red cell discriminant incorporating volume dispersion for differentiating iron deficiency anemia from thalassemia minor. Blood Cells. 1989, v.15, p.481495.

GUERRA - SHINOHARA E.M.; ANDREGUETTO, A.A.; PAGLIUSI, R.A.; D'AVILA, V.L.B. Importância dos parâmetros: amplitude de variação do tamanho dos eritrócitos (RDW) e dos histogramas de distribuição de volumes celulares, no diagnóstico das anemias. News Lab, São Paulo,1999, v.35, p.118 -126.

INTERNATIONAL COMMITTE FOR STANDARDIZATION IN HAEMATOLOGY. Recommendations for measurements of serum iron in human blood. British Journal of Haematology, London, 1978, v. 38, p. $291-94$.

LEE,R.G. Anemias microciticas e distúrbios caracterizados por metabolismo de ferro alterado. In: RICHARD LEE, G;BITHEL,T.C.; ATHENS,J.W.; LUKENS,J.N. WINTROBE - Hematologia Clínica. São Paulo, Manole, 1998, p.865-883.

LERNER, B.R. A alimentação e a anemia carencial em adolescentes. São Paulo, 1994. 90p. Tese (doutorado)-Faculdade de Saúde Pública, USP.

MARSH, W.L.; BISHOP, J.W.; DARCY, T.P. Evalution of red cell volume distribution width (RDW). Hematology Pathology., 1987,v.1, p.117 -123.

MCKENZIE, S.B. Textbook of hematology. $2^{\circ}$ ed. Baltimore, Williams \& Wilkins. 1996. 733 p.

MELO, M.R.; PURINI, M.C.; CANÇADO, R.D.; KOORO, F.; CHIATTONE, C.S. Uso dos índices hematimétricos no diagnóstico diferencial de anemias microcíticas: uma abordagem a ser adotada? Revista da Associação Médica Brasileira, São Paulo, 2002, v. 48, p.222-224. 
MILES, L.E.M.; LIPSCHILTZ, D.A.; BIEBER, C.P.; COOK, J.D. Measurement of serum ferritin by a 2 - site immunoradiometric assay. Analytical Biochemistry, 1974, v. 61, p. $208-209$.

NAOUM, P.C. Hemoglobinopatias e Talassemias, São Paulo. Sarvier, p.16-47, 2001.

PENTEADO, F.C.; LEITE A.A. padronização do método de solubilidade de hemoglobina $S$ em microplaca. Revista de Ciências Farmacêuticas, 2001. v. 22, no 2, p. 239 - 249.

PUNNONEN, K.; IRJALA, K.; RAJAMAKI, A. Serum transferrin receptor and its ratio to serum ferritin in the diagnosis of iron deficiency. Blood, Washington, 1997, v. 89, no 3, p.1051-1057.

RODAK, B.F. Diagnostic hematology. Philadelphia, Saundres. 1995, 720 p.

RUND, D.; FILON, D.; STRAUSS, N.; RACHMILEWITZ, E.A.; OPPENHEIM, A. Mean corpuscular volume of heterozygotes for $b$-thalassemia correlates with the severity of mutations. Blood, Washington,1992, v.79, p.238-243.

SILVA, V.P.F.; VALLES, L.M.A.T.; ESTEVÃO, I.F.; SOUTO, E.X.; BELTRÃO, A.C.; COTRIN, R.; DREGER, M.M,. HIRAI, F.N.; MATSUZAKI, C.A.; OBA, A.M.; OLIVEIRA,E.A.; SANO, M.; SHIINE, S.K.; STREIT, A.; YAMOTO,M. Correlação entre níveis de ferritina sérica e valores de RDW (red cell distribuition width), VCM (volume corpuscular médio) e Hb/Ht Hemoglobina/ hematócrito). News Lab, São Paulo,1997, v. 25, p. 123 - 127.

WEATHERALL, D.J. The thalassemias. British Medical Journal, London, 1997, v. 314, p.16751678. 